\title{
Sobre o impacto popular do fascismo ${ }^{1}$
}

Nicos Poulantzas

Um dos problemas mais importantes que o estudo do fascismo nos coloca, em razão ao mesmo tempo das dimensões reais do fenômeno e porque serviu de base a toda uma mitologia, é o do impacto popular do fascismo. Irei me limitar, nessas poucas linhas, a examinar os aspectos gerais, contentando-me em remeter o leitor ao meu livro Fascisme et dictadure, ${ }^{2}$ no qual esse problema é tratado detalhadamente.

Como eu dizia, o impacto popular do fascismo é um fenômeno real: entre outras, trata-se de uma das características distintivas essenciais do fascismo em relação aos outros regimes do Estado capitalista de exceção, de guerra aberta contra as massas populares (ditaduras militares, bonapartismos, etc.). De fato, o fascismo conseguiu subjugar aparelhos de Estado específicos de mobilização de massas (partidos, sindicatos, etc.), fenômeno que, em geral, não se encontra, ao menos na mesma medida e sob a mesma forma institucional (condicionando a própria forma de Estado), nos outros regimes de exceção. Isso implica precisamente que o fascismo teve, nas massas populares, uma aceitação que designarei provisoriamente pelo termo descritivo e neutro como impacto, porque, na verdade, é a própria natureza do fenômeno que deve ser estudada.

Isso nos leva a duas questões, que estão vinculadas:

a) Qual foi a dimensão e a natureza específica do fenômeno?

b) Quais foram as suas razões?

\footnotetext{
1 Publicação original: "A propos de l'impact populaire du fascisme" In: Maria Antonietta Macciocchi. Élements por une analyse du fascisme (tome I). Paris, Inédit, 1975. Traduzido por: Danilo Enrico Martuscelli.

${ }^{2}$ Nota do tradutor [N.T.]: trata-se do livro publicado no Brasil com o seguinte título: Fascismo e ditadura. São Paulo, Martins Fontes, 1978.
} 
Ora, existem atualmente duas tendências no estudo do fenômeno, errôneas ao mesmo tempo em relação à primeira e à segunda questões. Quanto à primeira questão, essas duas tendências apresentam algo em comum: elas não examinam seriamente nem o sentido desse impacto, nem o sentido de seu caráter popular. Elas aceitam como fato bruto e indiscutível, por um lado, que os fascismos teriam ganho, ao longo de toda sua existência e no mesmo grau, um apoio popular ativo, e, por outro, através de um emprego totalmente idealista dos termos massas e povo, admitem que esse apoio teria sido uniforme para todos os átomos dessa massa, sem qualquer distinção entre as classes, frações de classe e categorias sociais que constituem as massas populares. Quanto à segunda questão, elas dão explicações quer inteiramente errôneas do fenômeno, quer apenas parcialmente: de fato, perguntamo-nos se esses princípios ideológicos que regem as suas explicações, levam-nas a restringir o fenômeno real a um suposto apoio popular, uniforme e indiferenciado, das "massas" ao fascismo.

A. A primeira tendência, que é bastante antiga, mas que se encontra atualmente, entre outras, em numerosos textos da revista Tel Quel, ${ }^{3}$ é a da tentativa de explicação falsamente psicanalítica do fenômeno: o fato de que se trataria de explicar é por que as massas desejaram o fascismo. Ou melhor, a compreensão do fenômeno, sob essa formulação, é propriamente tributário de toda a verborragia ideológica atual sobre o desejo e solidário com uma certa concepção da relação entre marxismo e psicanálise, de que o freudo-marxismo termo explosivo pela própria conjunção implicada - nos deu já uma primeira prova. Essa tendência que supõe de algum modo, com fingida segurança, que o problema da relação entre ideologia e inconsciente está

\footnotetext{
${ }^{3}$ N. T.: trata-se de revista francesa publicada entre os anos de 1960 e 1982 . Exerceu papel importante no debate literário e também teórico-político, tendo sido marcada em sua trajetória por algumas influentes vertentes teóricas, entre as quais se destacaram: o estruturalismo, o freudismo e o maoismo. Em 1963, editores vinculados à revista passaram a publicar também a coletânea de livros que recebeu o mesmo nome da revista.
} 
resolvido, quando, na verdade, começa apenas a ser colocado em seu devido lugar, pode apenas fornecer explicação à falsa questão "por que as massas desejaram o fascismo", através da referência implícita à noção - absurda - de inconsciente coletivo: noção que instaura, de maneira artificial, uma relação entre os indivíduos que supostamente desejaram o fascismo - não se trata de classe - e as massas geradas por esses indivíduos - massas: o marxismo reconhece, mas as classes estão sempre ausentes -, massas essas que, uniforme e indistintamente, teriam supostamente aderido ao fascismo. Concepção de uma relação indivíduos-massas, que pelo vai e vem que implica entre psicologia individual e inconsciente coletivo (Psychologie des foules, de G. Le Bon, ${ }^{4}$ não está muito distante) perde, ademais, de vista totalmente o problema da relação entre ideologia e inconsciente.

B. A segunda tendência de explicação do fenômeno, sempre do mesmo modo circunscrita, isto é, como apoio indiferenciado e uniforme das massas ao fascismo - as classes estão sempre ausentes -, é aquela que privilegia a, se não se refere exclusivamente à linguagem empregada pelo fascismo em relação ao povo. Tendência que se encontra, entre outros, em J. P. Faye em seu livro Langages totalitaires ${ }^{5}$, e do qual fiz a crítica em outro lugar6. Trata-se de explicação em que, no fim das contas, comparece a velha utopia idealista para a qual são as ideias que fazem a história. O que, aliás, torna impossível o exame de um problema real, o do funcionamento preciso da ideologia fascista no impacto popular do fascismo. De fato, e voltaremos a isso, esse

\footnotetext{
${ }^{4}$ N. T.: trata-se do livro de Gustave Le Bon publicado no Brasil com o título: Psicologia das multidões. São Paulo, WMF Martins Fontes, 2019.

${ }^{5}$ N. T.: Este livro de Jean-Pierre Faye foi publicado no Brasil com o seguinte título: Introdução às linguagens totalitárias: teoria e transformação do relato. São Paulo, Perspectiva, 2009.

${ }^{6}$ N. T.: Nesta passagem, Poulantzas refere-se ao artigo: "Notes à propos du totalitarisme" In: Tel Quel, n. 53, 1973. Este texto foi originalmente publicado em português com o título: "Observações sobre o totalitarismo", na obra organizada por Antônio Edmilson Martins Rodrigues: Fascismo. Rio de Janeiro, Eldorado, 1974. Esta tradução foi também incorporada ao dossiê Nicos Poulantzas deste número dos Cadernos Cemarx.
} 
exame supõe a referência ao funcionamento de classe (em relação às diversas classes e aos seus subconjuntos ideológicos) dessa ideologia, enquanto que, para essa tendência, as ideias só podem fazer história se, e apenas se, no lugar do funcionamento de classe da ideologia, houver um verbo emitido por um - ou mais - sujeitos, indistintamente direcionado a, e percebido por, indivíduos-sujeitos, puros receptores indiferenciados desse verbo-ideia. É uma concepção que, aqui também, comanda a maneira como o fenômeno do impacto popular do fascismo é demarcado. Se, para a primeira tendência, a questão seria como e por que "as massas desejaram o fascismo", ela seria aqui como "o fascismo foi contado e dito às massas", isso explica por que ele foi disseminado por essas massas, consideradas global e indistintamente subjugadas pelo verbo fascista - permanecendo as classes sempre ausentes.

Num primeiro momento, tentarei, por minha conta, delimitar melhor esse fenômeno do impacto popular dos fascismos (nazismo alemão e fascismo italiano), antes de dizer duas palavras sobre as suas razões. Mas adiantarei que as minhas observações precedentes não devem nos conduzir a uma simplificação arbitrária do fenômeno, nem à sua redução ao fenômeno geral, bem conhecido, de certas ideologias reacionárias que encontram, em circunstâncias específicas, um eco nas classes populares e de que a adesão particularmente entusiasta das massas populares na França e na Alemanha à guerra interimperialista de 1914-1918, em seu início, nos oferece o exemplo característico. O impacto popular do fascismo, mesmo que participando desse fenômeno, apresenta aspectos muito particulares.

E, antes de tudo, no que concerne aos fatos reais:

1. É preciso distinguir entre as classes sociais que fazem parte das massas populares

a) Em primeiro lugar, a classe operária - ainda que seja necessário distinguir melhor suas camadas - foi muito menos contaminada pelo fascismo do que se pode sugerir, e, de qualquer modo, menos que as outras classes populares. Ela foi sempre consideravelmente sub-representada nos aparelhos (partidos, sindicatos) fascistas em

\begin{tabular}{l|l}
\hline 176 & Sobre o impacto popular do fascismo
\end{tabular} 
comparação à sua importância na população global da Alemanha e da Itália e, mesmo do ponto de vista eleitoral, os estudos rigorosos e sérios dos resultados das últimas eleições relativamente livres nesses dois países mostram que a classe operária permaneceu, em sua massa, fiel às suas organizações tradicionais, aos partidos comunistas e socialistas.

Mas, no caso da classe operária, há mais: durante o nazismo e o fascismo, houve uma resistência importante da classe operária, que, se apenas raramente tomou a forma de insurreição aberta e armada (os refúgios italianos), não se manifestou menos pelas formas subreptícias de resistência operária espontânea. Aqueles que decretam, pela classe operária, que ela "desejou" o fascismo, ignoram totalmente, é claro: as sabotagens e a queda da produção, o absenteísmo massivo, as greves selvagens, etc., criando problemas consideráveis para os dirigentes fascistas, como provam as medidas permanentes tomadas para preveni-las. Formas de resistência que, levando em conta a forma de Estado fascista, eram efetivamente formas de oposição política ao regime.

b) As classes populares do campo, pois sabemos que o próprio campesinato está dividido em camadas. Se o nazismo alemão em particular conseguiu alcançar um impacto popular sólido nas classes populares do campo nas regiões do Leste, da Prússia Oriental, onde as relações feudais marcavam uma presença notável, se, ainda, os fascismos alcançaram por vezes, mas de modo muito desigual, um eco em certos setores da pequena-burguesia rural, os famosos camponeses parcelares, em contrapartida, a grande massa do campesinato pobre, com os operários agrícolas à cabeça, permaneceu impermeável ao fascismo. O campesinato pobre ficou, também, sub-representado nos aparelhos fascistas e jamais se constituiu em base de sustentação do fascismo. Muito mais: o fascismo rural, na Alemanha e na Itália, se parece claramente com o fenômeno tradicional do "terror branco"7 dos grandes proprietários

\footnotetext{
${ }^{7}$ N.T.: refere-se a atos de violência praticados por grupos reacionários e conservadores que integram movimentos contrarrevolucionários.
} 
fundiários contra as classes populares do campo, que, massivamente, teriam ficado espantadas ao saberem que elas "desejaram" o fascismo.

c) A pequena burguesia tradicional (pequenos comerciantes e artesãos) e a nova (empregados, funcionários, etc.): ela inclina-se, efetivamente, de maneira massiva e aberta para o lado do fascismo, e encontra-se consideravelmente sobre-representada nos aparelhos fascistas, são sua base de sustentação. Em suma, a especificidade do fenômeno do impacto popular do fascismo, da relação fascismomassas populares, se reduz, no essencial, ao problema da relação entre o fascismo e a pequena burguesia, relação marcada, contudo, como veremos, por numerosas ambiguidades.

2. É preciso, ainda, distinguir, e eu o menciono, embora a meu ver seja um elemento secundário, em razão da importância atual dessas questões entre as diversas categorias sociais diferenciadas nas classes populares. É notadamente certo que o fascismo logra obter um impacto popular mais marcante na juventude, mas também na população feminina. Isso ocorre em razão, entre outras, das formas institucionais dominantes do aparelho familiar e do aparelho escolar e dos subsistemas ideológicos que reinavam, à época, nesses aparelhos na Alemanha e na Itália.

3. É preciso periodizar, no que se refere a esse impacto popular, o próprio fascismo, ao mesmo tempo o processo de fascistização e o fascismo estabelecido.

De fato, se, em razão, entre outras, da complexa ambiguidade político-ideológica das origens do fascismo, seu impacto evidenciase claramente ao longo do processo de fascistização - tendo em vista as observações formuladas anteriormente -, constata-se, não menos nitidamente, um processo de deserção em relação ao fascismo desde a primeira etapa do fascismo estabelecido, e na medida em que ele mostra abertamente sua feição antipopular, viragem aliás marcada por depurações massivas e sangrentas em suas próprias fileiras - episódio

178 Sobre o impacto popular do fascismo 
clássico da "noite das facas longas" ${ }^{8}$ na Alemanha. Processo de deserção que se traduz no recrudescimento da repressão sistemática, mas que, permanecendo ininterrupto e culminando ao longo da Segunda Guerra mundial, apresenta altos e baixos: assistimos notadamente a um aumento da popularidade do nazismo desde a Anschluss (anexação da Áustria) e do fascismo italiano desde a guerra da Líbia, por conta de razões nacionais complexas que aqui se transplantam. Se não se levar em consideração esse processo de deserção, não se compreenderá nada, por exemplo, do fenômeno repentino de uma Itália popular massivamente antifascista durante e depois da queda de Mussolini, e se será tentado a atribuí-lo, com o ímpeto de duvidosos escárnios, à versatilidade ou ao oportunismo do povo italiano.

4. Resulta enfim, do que precede, que é preciso, na verdade, questionar o próprio termo "impacto" popular que se associa ao fascismo.

De fato, mesmo quando houve "impacto", isso compreendia toda uma gama diversificada, que ia da adesão ativa e quase incondicional ao apoio circunstancial e à resignação passiva. Para não deixar de dizer nada sobre a neutralização forçada, na medida em a repressão recrudesce de maneira inacreditável: embora a repressão esteja, certamente, longe de explicar tudo, era preciso, ainda assim, lhe fazer referência nesses tempos em que os próprios judeus ficaram bastante espantados ao saberem por Liliana Cavani em seu filme Portier de nuit ${ }^{9}$ que eles não estiveram distantes de desejar o fascismo.

Sejamos mais sérios: poderíamos responder que a existência dessa gama diversificada do impacto popular do fascismo não tem

${ }^{8}$ N. T: trata-se de operação ocorrida no final de junho de 1934 e comandada por Hitler, que resultou na execução de dezenas de pessoas e na prisão de milhares de membros ligados à organização paramilitar Sturmabteilung (SA ou Tropa de Assalto) vinculada ao Partido Nazista. A ação foi arquitetada por outra organização paramilitar chamada Schutzstaffel (SS) que se tornou, a partir de então, o principal braço armado do militarismo alemão.

${ }^{9}$ Nota do tradutor: no Brasil, o título desse filme aparece como O porteiro da noite. 
real significado político, e que uma resignação passiva não difere tanto de uma adesão ativa quanto às suas repercussões sobre o fascismo estabelecido. Isso é inteiramente falso, pois precisamente enquanto fenômeno de massa, ou seja, para uma massa importante da população, essa resignação ombreou, de fato, permanentemente com uma resistência passiva, o que provocou progressivamente um certo isolamento do fascismo estabelecido nas classes e frações de classe onde ele havia obtido apoio. Isolamento que, por sua vez, acentuou consideravelmente as contradições internas do fascismo, traduzidas em toda uma série de falsas manobras (falsas manobras militares, inclusive) que contribuíram para precipitar a sua derrubada.

Vamos agora ao segundo aspecto do problema, o das razões do fenômeno do impacto popular do fascismo que abrange a sua natureza e a sua dimensão. Mencionarei apenas aqui simplesmente alguns pontos dispersos, que me parecem particularmente importantes.

1. A política econômica durante o primeiro período do fascismo estabelecido.

Se essa política consistia numa exploração consideravelmente crescente das massas populares, essa exploração foi, por um lado, para certas classes e frações de classes populares, principalmente relativa (visou o crescimento considerável dos lucros) e não absoluta (o poder real de compra foi, para certas classes populares, mantido por algum tempo), por outro, foi conduzida de acordo com uma estratégia diversificada, consistindo em dividir essas classes e frações e em conquistá-las à custa uma das outras. Mas a razão mais importante foi o êxito do fascismo (italiano desde a crise de 1920, alemão desde a crise de 1930) de tirar vantagem, de maneira espetacular, do desemprego que desempenhava um papel importante no processo de fascistização desses países. Essa superação relativa dessas crises econômicas pelo fascismo foi, certamente, alcançada, nesse período de transição do capitalismo concorrencial para o capitalismo monopolista, não apenas por uma política a serviço da concentração monopolista e

\begin{tabular}{l|l}
\hline 180 & Sobre o impacto popular do fascismo
\end{tabular} 
de agravamento da exploração das massas populares, mas também através de um esforço político de expansão econômica imperialista e de armamentos, que conduziu à Segunda Guerra mundial. Isso não impediu que, na época e por algum tempo, esse uso do desemprego jogasse um papel importante no impacto popular do fascismo.

2. As coordenadas reais, e a sua exploração pelos fascismos, da questão nacional.

Questão decisiva, cuja importância foi durante muito tempo subestimada pelo marxismo, e que, na Alemanha e na Itália, se revestia de uma forma particular, distinta daquela que se revestia em outros países imperialistas. E isso em dois aspectos:

Para começar, a unidade nacional característica do capitalismo, dado o processo de revolução democrática burguesa nesses dois países (Revolução pelo alto com Bismarck na Alemanha, Risorgimento perdido, na Itália), estava longe de se efetivar, no momento da ascensão do nazismo e do fascismo ao poder, no mesmo grau que nos outros países capitalistas desenvolvidos. Em certo sentido, o nazismo e o fascismo concluíram o processo de unidade nacional capitalista nesses dois países, o que foi certamente feito com as desigualdades internas de desenvolvimento características de qualquer processo semelhante, mas que lhes permite, contudo, posar como campeões da unidade nacional e de jogar plenamente com as ambiguidades desse nacionalismo em certas classes populares (classes populares do campo e pequena burguesia, especialmente). É, portanto, importante observar que os fascismos não deram apenas simplesmente a cartada de um nacionalismo imperialista agressivo e expansionista, mas igualmente a da unidade nacional, mais ambígua e complexa (Mussolini continuador de Garibaldi, Hitler de Bismarck), o que influiu consideravelmente no seu impacto popular.

Na sequência, é preciso apontar as consequências reais, sobre a conjuntura da questão nacional, do lugar da Alemanha e da Itália 
na cadeia imperialista depois da Primeira Guerra mundial ${ }^{10}$. No caso da Alemanha, a ocorrência do Tratado de Versalhes, de repercussões incalculáveis, caracterizado por Lênin como o ato de pilhagem mais monstruoso da história. No caso da Itália, o fato de que, tendo chegado atrasada no processo de estabelecimento e reprodução do capitalismo, ela sofria as consequências reais de uma exploração por parte do capital imperialista, massivamente implantado na Itália bem antes da ascensão do fascismo ao poder, o que, aliás, lhe valeu ser tratada como primo pobre desde o festim dos vencedores da guerra de 19141918 (o socialista Mussolini foi, durante a guerra, o representante da tendência intervencionista de esquerda defensora da participação da Itália na guerra). Apoiado nesses fatos reais, os fascismos puderam explorar a fundo o tema da ideologia das nações proletárias, tema que, na Alemanha, se revestiu mesmo, em certos setores da dita esquerda nacional-socialista, com conotações nitidamente antiimperialistas. Gregor Strasser, executado, aliás e não por acaso, durante a noite das facas longas, escrevia: "A indústria alemã, a economia alemã entre as mãos do capital financeiro internacional, é o fim de qualquer libertação social, é o fim de todos os sonhos de uma Alemanha socialista... Nós, revolucionários nacional-socialistas, nos engajamos na luta contra o capitalismo e o imperialismo, cuja encarnação é o Tratado de Versalhes... Nós, revolucionários nacional-socialistas, reconhecemos que existe uma ligação entre a liberdade nacional de nosso povo e a libertação econômica da classe operária alemã. $\mathrm{O}$ socialismo alemão só será possível e durável quando a Alemanha for livre". Em resumo, aqui também, o uso deturpado pelos fascistas, mas apoiado nos fatos reais, de um nacionalismo antiimperialista profundamente enraizado nas massas populares explica, por um lado, o seu impacto popular muito mais que o seu nacionalismo oficial abertamente imperialista, agressivo e expansionista.

\footnotetext{
${ }^{10}$ N. T.: No original, Poulantzas faz referência à Segunda Guerra Mundial, mas tal remissão não faz nenhum sentido para a lógica de argumentação desse parágrafo que procura discutir as condições de surgimento do fascismo.
}

\begin{tabular}{l|l}
\hline 82 & Sobre o impacto popular do fascismo
\end{tabular} 
3. A ideologia fascista e sua materialização institucional nos aparelhos de Estado fascistas

Para entender essa questão capital, é necessário, na verdade, especificar o funcionamento de classe dessa ideologia, e abandonar, de uma vez por todas, a concepção de um discurso ou linguagem fascista, unificada e uniforme, dirigida diretamente às massas. Tal como Togliatti apontava justamente na época, nada é mais falso do que considerar a ideologia fascista como um "sistema" unificado e unívoco: "A ideologia contém uma série de elementos heterogêneos... Eu lhes previno contra a tendência de considerar a ideologia fascista como qualquer coisa de solidamente constituída, de acabada, de homogênea...". ${ }^{11}$ De fato, não é, de modo algum, a qualquer repetição de um discurso idêntico, veiculado pelas técnicas de propaganda, diante das massas atomizadas e indiferenciadas, que se deve o papel da ideologia fascista nas massas populares, tal como, a meu ver, dá a entender um filme recente, contudo, antifascista e animado pelas melhores intenções, Fascista ${ }^{12}$. Muito pelo contrário, esse papel deve-se ao fato de que essas ideologias e discursos se apresentam de maneira consideravelmente diferenciada, tais como se incorporam aos diversos aparelhos político-ideológicos fascistas, de acordo com as diversas classes, frações de classe e categorias sociais a quem se dirigem, o que lhes permitiram precisamente explorar as condições de existência material dessas classes e frações. O discurso ideológico fascista é, na verdade, consideravelmente diferente, caso se dirija à classe operária e se incorpore aos aparelhos que lhes são especialmente destinados (sindicatos fascistas), às classes populares do campo ou à pequena burguesia (partido fascista). Nada de mais nítido do que o funcionamento de um mesmo tema, o do corporativismo que, sob a

\footnotetext{
${ }^{11}$ N. T.: Essas observações encontram-se em livro disponível em língua portuguesa: Palmiro Togliatti. Lições sobre o fascismo. São Paulo, Livraria Editora Ciências Humanas, 1978.

12 N. T.: Poulantzas refere-se ao filme Fascista, de Nico Naldini, exibido no ciclo de seminários organizado por Maria Antonietta Macciocchi na Universidade de Paris VIII, nos anos de 1974-1975, que deu origem ao livro onde consta o texto aqui publicado.
} 
aparência de uma pura e simples repetição, reveste-se, na verdade, de um sentido consideravelmente diferente, caso se dirija à classe operária, ao campesinato pobre ou à pequena burguesia.

É partir daí precisamente que o fascismo (e isso é um traço particular de seu funcionamento ideológico) pôde retomar em seu discurso ideológico, deturpando-as, uma série de aspirações populares profundas, frequentemente específicas de cada uma das classes, frações de classes e categorias sociais consideradas. Esse foi o caso dos temas autogestionários e de controle da produção pelos trabalhadores, das formulações socializantes contra a propriedade, o poder dos monopólios, o capital imperialista etc., evidenciado nas relações entre fascismo e classe operária, presentes notadamente na esquerda nacional-socialista na Alemanha e na ala anarcossindicalista do fascismo italiano. Esse foi o caso dos temas da unidade camponesa e dos laços de solo e de sangue contra a exploração do campo pela cidade, fundada sobre a contradição real indústriaagricultura e sobre a exploração, pelo capital, das classes populares do campo no processo de desenvolvimento do capitalismo na agricultura, evidenciado nas relações entre fascismo e classes populares do campo. Esse foi, igualmente, o caso dos numerosos exemplos evidenciados no discurso fascista especificamente direcionado à pequena burguesia.

No entanto, a fim de compreender melhor o funcionamento real (de classe) dessa ideologia fascista diferenciada, é preciso prestar a maior atenção nas estruturas institucionais nas quais essa ideologia se materializa, e não insistir na simples análise do discurso fascista, circulando pretensamente entre o emissor-chefe e as massas-receptoras. O que, além do mais, permitirá precisamente compreender a luta de classe intensa que atravessa permanentemente os aparelhos fascistas, e especificar ainda mais o sentido do impacto popular do fascismo.

Aqui também, no lugar de assistir a uma pura e simples uniformização unívoca dos diversos aparelhos de Estado fascistas, assistese, de fato, paralelamente à sua centralização no "topo", a um efetivo deslocamento e descentralização destes, segundo as classes, frações de classe e categorias sociais às quais eles se remetem principalmente. $\mathrm{Da}$

184 Sobre o impacto popular do fascismo 
família à escola, às organizações da juventude, aos aparelhos culturais e à Igreja, dos partidos aos sindicatos fascistas, da administração (aparelho burocrático do Estado) às forças armadas, dos $S A$ aos $S S$ (nazismo $)^{13}$ e à polícia política (milícias), descobre-se, na verdade, à sombra unificadora do discurso e do "princípio" do chefe, o emaranhado prodigiosamente contraditório de vários subconjuntos ideológicos regionais: o que tem como efeito a recuperação e o paralelismo constantes dos aparelhos, redes e correias de transmissão do poder, e cede lugar às contradições internas do fascismo. Em suma, é também esse sistema específico de enquadramento e de mobilização das massas populares, no interior do qual as classes, frações de classe e categorias sociais pensam poder se apropriar de um ou mais aparelhos específicos, ou utilizá-los a fim de fazer valer, ou impor, os seus próprios interesses, o que explica, por um lado, o impacto popular do fascismo.

Mas esse foco no exame dos aparelhos de Estado que materializam a ideologia fascista, permite precisamente compreender a luta de classe que os atravessa permanentemente, luta de classe que desaparece na concepção de um discurso unívoco e desencarnado dirigido às massas. Pode-se assim observar ainda melhor toda a ambiguidade do impacto popular do fascismo. De fato, mesmo onde houve impacto, e para as classes de frações consideradas e ativamente engajadas nos aparelhos fascistas, isso constantemente se deu concomitantemente resistência ao fascismo, mesmo quando essa resistência não assumisse, nesse caso, uma forma aberta, ocorrendo, no entanto, frequentemente em razão dessa diferenciação dos aparelhos, sob a forma de reivindicação, por parte dessas massas, do verdadeiro fascismo, fantasma no qual investiram as suas aspirações populares (como as constantes reivindicações da segunda revolução, anticapitalista, na Alemanha e na Itália). Para tomar um exemplo descritivo: um operário anarcossindicalista, membro convencido dos sindicatos fascistas, e que trava (identifica-se

${ }^{13} \mathrm{O}$ significado dessas siglas pode ser observado na nota de rodapé 7 e também num curto texto publicado na seguinte página: https:/contaroholocausto.wixsite.com/ holocausto/single-post/2017/04/01/As-guardas-SA-e-SS

cadernos cemarx, $\mathrm{n}^{\mathrm{o}} 12-2019$ 
vários casos sob o fascismo italiano) uma luta encarniçada contra os burocratas do partido e a milícia em nome de seu sonho corporativista - contra o poder do capital - e do que ele considera como fascismo puro e autêntico: ele adere ao fascismo ou muito pelo contrário resiste a ele, ou seja, resiste à sua verdadeira natureza e função de classe? Em todo caso, o próprio fascismo não se equivoca, o que se percebe nos expurgos, eliminações e reformas constantes que ele opera sobre seus próprios aparelhos. Em suma, eu o repito, o "impacto" popular do fascismo, manifesto na adesão de frações de classe populares aos aparelhos fascistas, conviveu constantemente com uma luta de classe intensa dessas mesmas frações contra o fascismo através desses próprios aparelhos. O que havia sido perfeitamente compreendido Dimitrov quando, no VII Congresso da Internacional, recomendou insistentemente aos comunistas a participação nos sindicatos fascistas a fim de, por dentro deles, travar a luta contra o fascismo. ${ }^{14}$

4. A política da Internacional Comunista e dos partidos comunistas italiano e alemão desde o advento do fascismo até, aproximadamente, o VII Congresso (1935) da Internacional Comunista.

O problema é muito importante para que eu possa tratá-lo nessas poucas linhas. Irei me limitar a duas palavras, referindo não à questão das responsabilidades dessa política pelo advento do fascismo, ou seja, o seu fracasso para impedir a ascensão, nesses dois países, do fascismo ao poder, mas à questão de seus efeitos sobre o impacto popular do fascismo: o que constitui uma questão relativamente diferente.

E direi, na sequência, que se essa política teve consequências diretas por seu fracasso em barrar à ascensão do fascismo ao poder, ela teve apenas efeitos indiretos sobre o impacto popular do fascismo. Entendo, com isso, que esse impacto não consistiu muito em,

\footnotetext{
${ }^{14}$ N. T.: para uma leitura deste informe, ver: Jorge Dimitrov. A luta pela unidade da classe operária contra o fascismo. Informe apresentado ante o VII Congresso Mundial da Internacional Comunista, a 2 de agosto de 1935. Belo Horizonte, Aldeia Global, 1978.
}

\begin{tabular}{l|l}
\hline 186 & Sobre o impacto popular do fascismo
\end{tabular} 
nitidamente, fazer inclinar certas classes e frações de classe populares para o fascismo, por causa do medo do comunismo ou do bolchevismo, ainda que esse elemento insira-se, bem entendido, em uma parte desse impacto, e constitua, aliás, um elemento essencial da ideologia dos regimes fascistas. O que é, de outra maneira, mais importante de observar, é que, de fato, certas classes populares que se inclinaram para o lado do fascismo, fizeram-no em razão do insucesso dos partidos comunistas italiano e alemão por não atingirem seus objetivos revolucionários e iniciarem um processo de transição ao socialismo. Essas frações haviam considerado, diante dessa privação, na verdade, que o fascismo seria mais apto a atender os seus objetivos: amplos conjuntos dessas frações transferiram, durante um tempo, suas aspirações revolucionárias para o fascismo. É nisso que reside precisamente a ambiguidade colossal da relação inicial dessas massas com o fascismo, e não se compreende nada do impacto popular do fascismo, se o assimilar, pura e simplesmente, ao menos nas massas urbanas, a um "guardismo branco"15 de bandas armadas do capital. Esse é provavelmente um dos aspectos da análise penetrante que Clara Zetkin fez do fascismo, no III Pleno (1923) da Internacional Comunista: "O fascismo é muito diferente da ditadura de Horthy na Hungria... O fascismo não é, absolutamente, a vingança da burguesia contra o proletariado insurgido de maneira combativa. Considerado do ponto de vista histórico e objetivo, o fascismo surge mais porque o proletariado não conseguiu levar adiante a sua revolução"16.

Desse ponto de vista, a responsabilidade da política do Partido Comunista Italiano, contrário, na época da instauração do fascismo, à política da Internacional, ainda sob a égide de Lênin, e do Partido Comunista Alemão, sob a instigação direta da Internacional, não foi

\footnotetext{
${ }^{15}$ N. T.: referência ao Exército branco ou Guarda branco russo, formado por forças nacionalistas, conservadoras e contrarrevolucionárias que lutaram contra o Exército Vermelho depois da deflagração da Revolução de Outubro.

${ }^{16} \mathrm{~N}$. T.: $\mathrm{O}$ texto mencionado de Clara Zetkin encontra-se disponível em língua portuguesa no sítio: https://www.marxists.org/portugues/zetkin/1923/08/fascismo. htm
} 
tanto ter desviado as massas dos objetivos revolucionários e provocado nelas reflexos reacionários, mas, no essencial, ter deixado essas massas populares desorientadas e desarmadas face à recuperação ideológica deturpada pelo fascismo de aspirações populares profundas, e tê-las, assim, deixado ser atraídas por uma política a serviço do grande capital. O que equivale a dizer que esses partidos não souberam, durante muito tempo, travar uma luta político-ideológica eficaz contra o fascismo. Mas é evidente que não posso, nessa curta exposição, nem mesmo aflorar as razões complexas dessa situação, razões das quais eu tratei longamente em outro lugar. ${ }^{17}$

${ }^{17}$ N.T.: Poulantzas refere-se novamente aqui à obra Fascismo e ditadura, op. cit. 